\title{
Human Lymphocyte Antigen DR Types in Relation to Early Clinical Manifestations in Diabetic Children
}

\author{
J. LUDVIGSSON AND B. LINDBLOM \\ Department of Pediatrics, University of Linköping [J.L.] and the Swedish Government Laboratory for Forensic \\ Chemistry, University of Linköping [B.L.]
}

\begin{abstract}
Human lymphocyte antigen (HLA)-DR-typing was performed in 117 insulin-dependent diabetics with age at onset between 0.5 and 17 years (mean \pm SD, $9.0 \pm$ 3.9); 115 of 117 patients were DR3- and/or DR4-positive. DR4 was very common, seen alone or in combination with other DR types in $82.9 \%$ of the patients. Only two children were DR2-positive, but they also were DR4-positive. A comparison between DR3 and DR4 patients showed that DR4 patients manifested a seasonal variation of onset (most common onset during spring and autumn), had more severe signs and symptoms of the disease at onset, and were less likely to have a partial remission than patients with DR3. The results support the hypothesis that insulindependent diabetes mellitus is a genetically heterogeneous disease. (Pediatr Res 18:1239-1241, 1984)
\end{abstract}

\section{Abbreviations}

HLA, human lymphocyte antigen

IDDM, insulin-dependent diabetes mellitus $\mathbf{R R}$, relative risk

It is well established that carriers of certain HLA types have an increased risk of developing insulin-dependent diabetes mellitus. Thus, B8 and B15 are significantly overrepresented $(3,9)$ and B7 is rare (6) among patients with IDDM. Recently, it has been shown that IDDM is even more closely associated with DR3 and DR4, while DR2 is almost never found. $(2,10,11)$. Most earlier studies were conducted in patients with adult onset. We wanted to study diabetic children, a more homogeneous group, to assess whether there are any differences in the early manifestations of the disease between patients with HLA-DR3 and HLA-DR4 haplotypes.

\section{PATIENTS AND METHODS}

The study included 117 insulin-dependent diabetic children, 58 girls and 59 boys. As all juvenile diabetics of the areas come to our clinic, there was no selection of patients. Thus, these patients presumably were representative of IDDM patients in Sweden. Ages at onset varied between 0.5 and 17 years (mean \pm $\mathrm{SD}, 9.0 \pm 3.9)$. The blood glucose level at onset ranged from $13.9-60.0 \mathrm{mmol} / \mathrm{liter}(25.0 \pm 11.5)$ and $85 \%$ of the patients had

Received December 29, 1983; accepted May 18, 1984.

Correspondence may be addressed to Johnny Ludvigsson, M.D., Department of Pediatrics, University Hospital, S-581.85 Linköping, Sweden.

This study was supported by the Swedish Diabetic Association and Swedish Research Council Grant 19X-04528-07B. ketonuria. Mean blood glucose for all patients during the first 7 hospital days was $7.8 \pm 3.7 \mathrm{mmol} /$ liter. All patients were treated with monocomponent insulin (Novo), diabetic diet, and the recommendation of physical exercise. With few exceptions, the patients tested their urine every day with Clinitest (2-drops method). The results were registered in a diary reviewed by the doctor at the hospital visit every 2-3 months. In addition, during the last 4 years, several patients conducted blood glucose measurements at home. All home tests were validated by hemoglobin A1 measurements.

Control data were developed from 151 healthy Swedish subjects in whom HLA-A-B-C-DR and MT frequencies were measured.

HLA-A-, B-, and C-typing was performed on Ficoll-Paque (Pharmacia Fine Chemicals) separating lymphocytes according to the method described by Kissmeyer-Nielsen and Kjerbye (5) as well as with National Institutes of Health techniques slightly modified for Hamax trays (Hamax Industries, Moss, Norway). HLA-DR and MT typing was performed on T-cell-depleted lymphocyte suspensions according to the long workshop protocol with slight modifications for Hamax trays. Partial remission has been defined (according to the recommendation of the International Study Group of Diabetes in Children and Adolescents) as a continuous period of at least 1 month early after onset with absent or minimal glucosuria and an insulin requirement of less than $0.5 \mathrm{IU} / \mathrm{kg}$ body weight $/ 24 \mathrm{~h}$. (1)

Statistics. The relative risk (RR) values have been calculated according to Woolf (15) and Svejgaard et al. (13) and indicate the relative frequency of the disease in a group of individuals carrying the antigen relative to a group lacking it. The significance of the difference between a given HLA frequency in the patient and control populations was evaluated by Fisher's $\chi^{2}$ test with Yeates' correction for a two by two contingency table. Corrected $p$ values $\left(p_{\text {corr }}\right)$ were calculated for antigens previously unknown to have any relationship to IDDM.

In the analysis of relations between HLA types and clinical manifestations, we have used the $\chi^{2}$ tesi and multiple regression analysis. Multiple regression analysis was used in an effort to relate the dependent variable to a function of background variables. Results are presented (Table 4) as the observed values of Student's $t$ test, partial correlation coefficients, and associated $p$ values. The correlation coefficient serves as an estimate of the correlation between two variables in samples comprising individuals who are alike with respect to the remaining background variables considered.

\section{RESULTS}

Antigen frequencies and relative risk values are shown in Table 1. As expected, the frequencies of the antigens B8, B15, Cw3, 
Table 1. HLA-A, $-B,-C$, and $-D R$ antigen frequencies in patients with juvenile insulin dependent diabetes (a) and controls (b) with calculated $R R$ values

\begin{tabular}{|c|c|c|c|c|c|}
\hline HLA & $\begin{array}{l}\text { Patients } \\
(n=117) \\
\text { (a) }\end{array}$ & $\mathrm{RR}$ & $\begin{array}{l}\text { Controls } \\
(n=151) \\
\text { (b) }\end{array}$ & \multicolumn{2}{|c|}{ Significance } \\
\hline Al & 0.30 & 1.25 & 0.25 & & \\
\hline A2 & 0.71 & 1.42 & 0.64 & & \\
\hline A 3 & 0.19 & 0.87 & 0.22 & & \\
\hline A9 & 0.22 & 1.19 & 0.19 & & \\
\hline $\mathrm{A} 10$ & 0.07 & 0.57 & 0.11 & & \\
\hline All & 0.03 & 0.84 & 0.04 & & \\
\hline A28 & 0.12 & 1.06 & 0.11 & & \\
\hline Aw19 & 0.13 & 0.61 & 0.19 & & \\
\hline B5 & 0.07 & 0.51 & 0.13 & & \\
\hline B7 & 0.16 & 0.50 & 0.28 & & \\
\hline B8 & 0.39 & 3.07 & 0.17 & $\chi^{2}=15.0$ & $p<0.0001$ \\
\hline $\mathrm{B} 12$ & 0.16 & 0.41 & 0.32 & $\chi^{2}=7.9$ & $p \approx 0.015$ \\
\hline B13 & 0.02 & 0.42 & 0.04 & & \\
\hline B14 & 0.01 & 0.20 & 0.04 & & \\
\hline B 15 & 0.41 & 2.36 & 0.23 & $\chi^{2}=9.5$ & $p \approx 0.001$ \\
\hline Bw16 & 0.08 & 1.46 & 0.06 & & \\
\hline B17 & 0.03 & 0.47 & 0.05 & & \\
\hline $\mathrm{B} 18$ & 0.14 & 1.82 & 0.08 & & \\
\hline Bw21 & 0.07 & 2.67 & 0.03 & & \\
\hline Bw22 & 0.03 & 1.28 & 0.02 & & \\
\hline $\mathrm{B} 27$ & 0.08 & 0.46 & 0.15 & $\chi^{2}=3.0$ & $p<0.06$ \\
\hline Bw35 & 0.06 & 1.52 & 0.04 & & \\
\hline B37 & 0.03 & 1.73 & 0.02 & & \\
\hline $\mathrm{B} 40$ & 0.24 & 1.51 & 0.21 & & \\
\hline B41 & 0.01 & & & & \\
\hline Cwl & 0.03 & 0.28 & 0.09 & & \\
\hline $\mathrm{Cw} 2$ & 0.09 & 0.57 & 0.15 & & \\
\hline $\mathrm{Cw} 3$ & 0.60 & 2.29 & 0.40 & $\chi^{2}=10.3$ & $p \approx 0.001$ \\
\hline Cw4 & 0.08 & 2.24 & 0.04 & $\chi^{2}=1.7$ & \\
\hline Cw5 & 0.05 & 1.07 & $0.06 \dagger$ & & \\
\hline Cw6 & 0.11 & 0.93 & $0.12 \dagger$ & & \\
\hline DR1 & 0.16 & 0.84 & 0.19 & & \\
\hline $\mathrm{DR} 2$ & 0.02 & 0.04 & 0.30 & $\chi^{2}=34.4$ & $p<0.0001$ \\
\hline DR3 & 0.54 & 4.23 & 0.22 & $\chi^{2}=28.7$ & $p<0.0001$ \\
\hline DR4 & 0.81 & 8.06 & 0.35 & $x^{2}=55.5$ & $p<0.0001$ \\
\hline DR5 & $0.02 *$ & 0.16 & $0.12 \dagger$ & & \\
\hline DR7 & 0.03 & 0.11 & 0.25 & $\chi^{2}=22.2$ & $p<0.0001$ \\
\hline DR8 & $0.04^{*}$ & 0.27 & $0.14 \uparrow$ & & \\
\hline DRw9 & $0.03^{*}$ & 1.56 & $0.04 \dagger$ & & \\
\hline MT1 & $0.23^{*}$ & 0.50 & $0.38 \dagger$ & & \\
\hline MT2 & $0.62 *$ & 1.75 & $0.48 \dagger$ & & \\
\hline MT3 & $0.85^{*}$ & 6.71 & $0.46 \dagger$ & $\chi^{2}=15.6$ & $p_{\text {corr }}<0.0042$ \\
\hline
\end{tabular}

$* n=49$.

$\dagger n=51$.

DR3, and DR4 are increased and those of B12, B27, DR2, and DR7 are decreased. The MT3 antigens, as defined by sera of the 8th Histocompatibility Workshops, is more frequent among the IDDM patients than among the controls (corrected $p$ values of 0.0042). Observed and expected DR phenotype combinations are shown in Table 2. HLA-DR types in relation to age at onset of diabetes are illustrated in Figure 1. Thus, DR4 is especially common among children with very early onset, e.g., before the age of 5 years, and during puberty, whereas children with DR3,4 have an incidence peak in prepuberty. Children with DR3 manifest no clear tendency.

Seasonal variation of onset (diagnosis) data are shown in Figure 2. While DR3 patients fall ill at various times during the year, there is a tendency for DR4 patients to have diabetes diagnosed during the spring and autumn months (Table 3). DR3,4 patients have diabetes diagnosed most often during summer and winter months. Some infections, usually regarded as viral during the last 3 months before onset, were recorded in 38 patients. Two patients, both with DR3, had mumps 2-3 months before onset of IDDM. There were no other relationships between infections and HLA-DR types. Patients with DR3 alone had mild symptoms at onset, and manifested a lower prevalence of ketonuria $(p<0.01)$ (Table 3$)$. Patients with DR3 more commonly had a

Table 2. Observed and expected DR phenotype combinations among 117 IDDM patients

\begin{tabular}{crrrr}
\hline Phenotype & Observed & Expected & \multicolumn{1}{c}{$\chi^{2}$} & \\
\hline 1 & 0 & 8.1 & 8.1 & \\
1,2 & 0 & 3.7 & 3.7 & \\
1,3 & 3 & 2.7 & 0.03 & \\
1,4 & 13 & 4.5 & 12.5 & \\
1,7 & 1 & 2.8 & & \\
2 & 0 & 14.6 & 14.6 & \\
2,3 & 0 & 4.5 & & \\
2,4 & 2 & 7.4 & & \\
2,7 & 0 & 4.7 & & \\
3 & 15 & 9.9 & 2.6 & $0<0.0001$ \\
3,4 & 45 & 5.3 & 297 & \\
3,7 & 0 & 3.4 & & \\
4 & 34 & 18.3 & & \\
4,7 & 3 & 5.6 & & \\
7 & 0 & 10.8 & & \\
,-- & 1 & 10.8 & & \\
& & & & \\
\hline
\end{tabular}

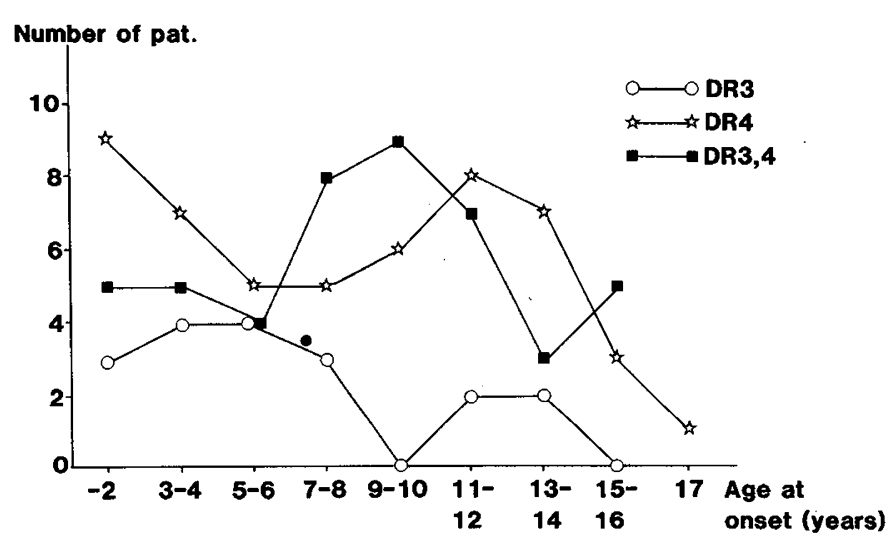

Fig. 1. Age at onset of IDDM in 115 patients who have the HLADR types 3 or 4 or 3,4 .

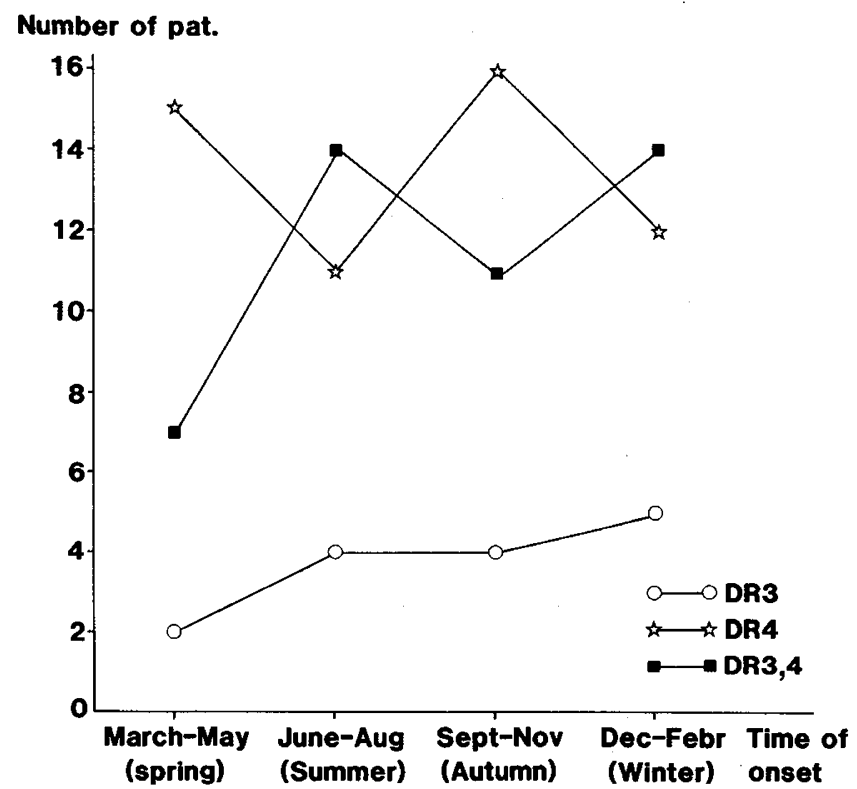

Fig. 2. Seasonal variation of onset of IDDM in 115 children in relation to their HLA-DR types. 
Table 3. A comparison between $H L A-D R 3$ and $-D R 4$ regarding early clinical manifestations and course

\begin{tabular}{|c|c|c|c|}
\hline & $\begin{array}{c}\text { DR } 3 / 0 \\
\text { or } 3 / 3\end{array}$ & DR 4/not 3 & \\
\hline $\begin{array}{l}\text { Diagnosis in spring } \\
\text { (March-May) and } \\
\text { autumn (Oct.-Nov.) }\end{array}$ & $4 / 15$ & $26 / 52$ & $p<0.05$ \\
\hline No ketonuria at onset & $4 / 15$ & $3 / 52$ & $p<0.02$ \\
\hline $\begin{array}{l}\text { Severe symptoms at on- } \\
\text { set }\end{array}$ & $0 / 15$ & $7 / 52$ & $p<0.10$ \\
\hline $\begin{array}{l}\text { Partial remission without } \\
\text { glucosuria in } 100 \% \\
\text { of daily tests }\end{array}$ & & & \\
\hline$>1$ month & $7 / 15$ & $4 / 52$ & $p<0.001$ \\
\hline$>6$ months & $6 / 15$ & $2 / 52$ & $p<0.001$ \\
\hline $\begin{array}{l}\text { Partial remission without } \\
\text { glucosuria in } 90 \% \text { of } \\
\text { daily tests }>1 \\
\text { month }\end{array}$ & $9 / 15$ & $11 / 52$ & $p<0.01$ \\
\hline
\end{tabular}

Table 4. Partial remission in relation to some clinical parameters and $H L A-D R 3$

\begin{tabular}{lrrr}
\hline & $t$ & $r$ & $p$ \\
\hline Age at onset & 0.70 & 0.07 & NS \\
Sex (boys $>$ girls) & 0.68 & 0.07 & NS \\
Duration of ketonuria & -1.01 & -0.10 & NS \\
Monocomponent insulin & 1.82 & 0.19 & $<0.1$ \\
$\quad$ from the onset & & & \\
HLA-DR3 & 2.12 & 0.22 & $<0.05$ \\
\hline
\end{tabular}

partial remission $(p<0.01)$ which persisted longer than 6 months $(p<0.001)$ compared to other patients. This DR3 relationship to remission could be seen even when other factors of importance were kept constant (Table 4). Patients with DR3,4 had a picture more similar to DR4 than DR3 patients with about the same tendency to ketonuria and severe symptoms during the 1st wk and less frequent remission.

\section{DISCUSSION}

Our results on Swedish children confirm earlier studies that DR 3 and DR4 alone or in combination are much more common in insulin-dependent diabetics than in healthy controls. These markers were demonstrated in 115 of 117 diabetic children, a prevalence more common than reported from studies of adults. Some 97 of $117(82.8 \%)$ had DR4 alone or in combination with some other antigen, while only 15 patients had DR3 alone. Only two patients had DR2 but both also had DR4.

The increased MT3 frequency in the patient group probably is caused by the strong association between the MT3 and DR4 antigen (4). However, it is not yet ruled out whether the serological reactions defining the MT specificities are due to antigens from a single locus or include products from several DR-linked loci (14). In patients with onset at younger than the age of 5 years, DR 4 alone predominates, while a combination DR3,4 is more frequent in children with disease onset during school age with a peak in prepuberty. In children with onset during early puberty, DR4 also is common. Not only is there a different age at onset among patients with different HLA-DR types, there are seasonal variations of onset and differences in severity of the disease at diagnosis in relation to HLA-DR types. These tendencies support the hypothesis that patients with DR3 and DR4 have two different types of IDDM, maybe with different etiologies (2). Thus, while we found no seasonal variation among the DR3 patients we do see such a variation for DR4 patients as well as a parallel seasonal tendency in those patients with both DR3 and DR4. The incidence peaks during spring and autumn in our group of patients with DR4 has usually been regarded as associ- ated with the occurrence of virus infections and thus has come to be regarded as support for the hypothesis that a virus is involved in the etiology (8). This could fit well with the tendency of DR4 patients to develop IDDM very early in life as children are exposed to many virus infections. However, there are other possible etiological mechanisms. The incidence curve in Figure 1 for DR4 patients is reminiscent of the growth velocity curves during different periods of childhood. The known seasonal variation of growth in normal children may well fit together with the seasonal variation of onset of IDDM. The parallel seasonal tendency of diabetes. onset between DR4 and DR 3,4 can only be speculated upon. Either this is quite random, or patients with both DR3,4 might get their disease somewhat earlier after the triggering mechanism: they have both the features associated with DR4 and with DR3. Another possibility would be that patients who are DR4 homozygotes are more susceptible to $\beta$ cell destruction because of viral infections. Those patients with DR 3,4 develop their disease a bit later; the initial damage is less severe but sufficient to initiate a process which gradually destroys the $\beta$-cells.

Our observation that DR4 patients tend to have more severe disease at onset (higher blood glucose levels, more frequent ketosis and severe symptoms) than patients with DR3 could be interpreted either as an indication of a more dramatic onset among the DR4 patients (e.g. because of an infection) or as a result of a more gradual onset of IDDM in patients with DR3. In any case, our results suggest that patients with DR3 have a different type of diabetes with less severe onset and a greater likelihood of partial remission, perhaps because of less pronounced $\beta$-cell damage (12).

HLA-B8 and DR3 have been found to be associated with islet cell antibody persistence (7), and it has been proposed that there should be a heterogeneous immunopathogenesis of IDDM, with HLA-DR3 predisposing to endocrine or autoimmune disease and DR4 to increased viral damage susceptibility (2). Our results are in accordance with such a hypothesis, although it should be pointed out that mechanisms other than viral infections, such as hormonal variations, may play a role for the onset of IDDM in individuals with HLA-DR4.

\section{REFERENCES}

1. Akerblom H 1980 The definition of remision. Presentation at the 5th Annual Meeting of the International Study Group of Diabetes in Children and Adolescents, Berlin.

2. Bertrams J, Sodomann P, Gries FA, Sachsse B, Jahnke K 1981 HLA-association of insulin dependent diabetes mellitus type I. Dtsch Med Wochenschr 106:927-932

3. Cudworth AG, Woodrow JC 1975 Evidence for HLA-linked genes in "juvenile" diabetes mellitus. Br Med J 111:133-135

4. Dick H 1982 HLA-DR: more than three loci? Immunol Today 3:199-203

5. Kissmeyer-Nielsen E, Kjerbye KE 1967 Purification of lymphocytes by flotation. In: Histocompatibility Testing. Munksgaard, Copenhagen, pp 381-382

6. Ludvigsson J, Säfwenberg J, Heding LG 1977 HLA-types, C-peptide and insulin antibodies in juvenile diabetes. Diabetologia 13:13-17

7. Ludwig H, Schernthaner G, Mayr WR 1979 Ia-type alloantigens and humoral autoimmune responsiveness in insulin-dependent diabetes mellitus. Metabolism 28:797-800

8. Maugh TH 1975 Diabetes: epidemiology suggests a viral connection. Science 188:347

9. Nerup J, Plats P, Ortved Andersen O, Christy M, Lyngsøe J, Poulsen JE, Ryder LP, Thomsen M, Staub Nielsen L, Svejgaard A 1974 HLA-antigens and diabetes mellitus. Lancet 2:864-866

10. Platz P, Jakobsen BK, Morling N, Ryder LP, Svejgaard A, Thomsen M, Christy M, Kromann H, Benn J, Nerup J, Green A, Hauge M 1981 HLA-D and $\mathrm{DR}$ antigens in genetic analysis of insulin dependent diabetes mellitus. Diabetologia 21:108-115

11. Sachs JA, Cudworth AG, Jaraquemada D, Gorsuch AN, Festenstein H 1980 Type I diabetes and the HLA-D locus. Diabetologia 18:41-43

12. Schernthaner $G 1982$ The relationship between clinical, immunological and genetic factors in insulin-dependent diabetics. In: Köbberling and Tattersall (eds) The Genetics of Diabetes Mellitus. Academic Press, London, pp 99114

13. Svejgaard A, Jersild C, Staub Nielsen L, Bodmer WF 1974 HLA-antigens and disease. Statistical and genetical considerations. Tissue Antigens 4:95-105

14. Trowsdale J, Lee J, McMichae] A 1983 HLA-DR bouillabaisse. Immunol Today 3:31-35

15. Woolf B 1955 On estimating the relation between blood group and disease. Ann Hum Genet 19:251-253 